\title{
Some aspects of the VVER-440 reactor plant life re-extension: a case study of the Novovoronezh NPP Unit $4^{*}$
}

\author{
Vladimir P. Povarov ${ }^{1}$, Anatoly I. Fedorov ${ }^{1}$, Sergey L. Vitkovsky ${ }^{1}$ \\ 1 Branch of JSC "Concern Rosenergoatom" "Novovoronezh Nuclear Power Plant", 1 Promyshlennaya zona Yuzhnaya, Novovoronezh, Voronezh \\ reg., 396072 Russia \\ Corresponding author: Vladimir P. Povarov (povarovvp@nvnpp1.rosenergoatom.ru)
}

Academic editor: Yury Kazansky • Received 6 June 2019 • Accepted 10 August 2019 • Published 25 September 2019

Citation: Povarov VP, Fedorov AI, Vitkovsky SL (2019) Some aspects of the VVER-440 reactor plant life re-extension: a case study of the Novovoronezh NPP Unit 4. Nuclear Energy and Technology 5(3): 249-256. https://doi.org/10.3897/nucet.5.46380

\begin{abstract}
The re-modernization of Unit 4 at the Novovoronezh NPP (Novovoronezh-4) made it possible to take a new approach to the problem of extending the VVER-440 reactor plant life and operation. The authors analyze the existing problems of the VVER-440/179 power unit, showing possible solutions to the identified shortcomings and the final state of the updated power unit. Modernization works significantly expanded the range of design-basis accidents from the primary coolant leak from an opening $(\mathrm{DN}=100 \mathrm{~mm})$ to the maximum possible, associated with a rupture of the main circulation pipelines $(\mathrm{MCP})(\mathrm{DN}=500 \mathrm{~mm})$. A unique experience was gained in using the safety systems of Unit 3 , which was finally shutdown for decommissioning, to increase reliability and provide additional redundancy for the safety systems of Unit 4.

The results of the performed works showed the correctness of the adopted concept of re-extending the service life of Unit 4 and ensured its compliance with the modern safety requirements in nuclear power engineering, including as it relates to the safety impact of the first-level probabilistic safety analysis model (PSA-1) for internal initiating events.
\end{abstract}

\section{Keywords}

Life re-extension, VVER-440, V-179, fluence, radiation embrittlement, safety systems, reactor vessel annealing

\section{Introduction}

In 2019, the Novovoronezh nuclear power plant (NvNPP) celebrates the 55th anniversary of its first power unit commissioning. During this time, the entire VVER line from the VVER-210 to the VVER-1200 was tested at the NPP. The authors attempt to summarize the problems associa- ted with NvNPP Unit 4 life re-extension, showing possible solutions to complex technical problems and analyzing the gained experience, which should be necessarily replicated for all domestic VVER designs to extend their service life up to 60 years. 
The first conceptual studies related to water-cooled power reactor plants started in the USSR as early as in 1954 (the year of the launch of the world's first nuclear power plant with an AM-1 uranium-graphite reactor) and were based on the submarine reactor pilot projects. In September 1955, an updated specification was issued for the VVER reactor, and in 1957, the NvNPP construction began. The entire start-up process of the first NvNPP power unit with a VVER-210-type reactor took less than four months: the physical start-up took place on September 8, the power start-up was on September 30, and the commissioning was on December 27, 1964. The theoretical and practical study of the VVER technology at the NvNPP led to the commissioning of Unit 2 with a capacity of 365 MW (VVER-365) in 1969 and Unit 3 with a VVER-440/179 reactor in 1971, which gave rise to a full-scale series of nuclear power units that have spread not only in the territory of the USSR but also in many European countries. As result of the sequential commissioning of Unit 4 with a VVER-440 reactor in 1972 and Unit 5 (VVER-1000) in 1980, the NvNPP reached a total capacity that allowed it to be considered the most powerful nuclear power plant in Europe at that time interval. In 2016, the Generation 3+ VVER-1200 power unit was started up. Thus, currently, the NvNPP has the following configuration: the VVER-210 (Unit 1) and the VVER-365 (Unit 2) were decommissioned in 1984 and 1990, respectively; the VVER-440 (Units 3 and 4) underwent the service life extension procedure in 2001 and 2002, respectively, for 15 years; in 2017, Unit 3 was shut down for decommissioning and Unit 4 underwent a repeated procedure for extending its service life for another 15 years (Collection of reports 2014). The service life of the VVER-1000 (Unit 5) has been extended for 15 years. One most advanced VVER-1200 (Unit 6) is in operation while the other VVER-1200 (Unit 7) is at the pre-commissioning stage. As the above historical background shows, the NvNPP has accumulated a unique experience in extending the equipment service life, and primarily of the VVER-440 power units which constitute a significant part of the reactor fleet at both Russian NPPs and NPPs built under Soviet projects in Eastern Europe.

\section{Initial design solutions for NVNPP Units 3 and 4 (V-179)}

In January 1966, based on the technical specifications, OKB Gidropress developed a technical design of the VVER-440 reactor for typical nuclear power plants with two units of $400 \mathrm{MW}$ each, and it was decided to use the VVER-440 (V-179) design for Units 3 and 4. For serial power units of NPPs with VVER-440 being built in our country and abroad, a new reactor design, V-230, was developed, which took into account the requirements of foreign customers in addition to the domestic ones (Ovchinnikov and Semenov 1988).

The VVER-440/179 reactor design was developed on the basis of the accumulated experience in designing, manufacturing, installing, commissioning, and operating the VVER-210 and VVER-365 reactor plants previously developed by OKB Gidropress and operated at the NvNPP site. At the same time, a number of design solutions met the recommendations of the IAEA INSAG-5 Report for future NPPs, published only in 1992, the main ones being as follows:

- the VVER-440/179 reactor (hereinafter the abbreviation 'VVER-440' will be referred only to the V-179 design) has a small core that is slightly exposed to xenon oscillations, which made it possible to avoid the necessity for local neutron flux control; the reactor is stable and has powerful negative feedback links, which creates favorable operating conditions in transient states;

- the reactor has a highly efficient safety ensured by a large number of elements of the control and protection system (CPS); the efficiency of the mechanical control system is sufficient to prevent the reactor from entering into re-criticality in accidents with any initiating events, including the failure of one of the most efficient CPS elements;

- the reactor safety trip is based on the gravitational principle and does not require additional energy sources;

- the core power density is low enough to provide a significant departure from nucleate boiling ratio on fuel rod claddings in any transient conditions; and

- a large specific volume of the primary and secondary coolant per unit thermal power of the reactor provides passive reactor core cooling for a long time and decreases dependence on the operator's early actions.

As the maximum design-basis accident, a leak of the DN100 pipeline with a DN32 restrictive insert was postulated, and the core damage frequency (CDF) was assumed to be $1.08 \cdot 10^{-3}$ reactor-years ${ }^{-1}$, which corresponded to the safety standards and regulations of the $60 \mathrm{~s}$.

\section{The concept and implemented decisions on modernization of Units 3 and 4 to extend their service life up to 45 years}

The VVER-440 design was based on the concept that by ensuring the high quality of the reactor plant equipment and components, their efficient operation and condition monitoring of the metal and equipment welds, it is possible to avoid their heavy damage and, therefore, eliminate the possibility of a severe accident. 
The work on extending the service life of Units 3 and 4 had begun long before they expired their design life of 30 years, assuming the following sequence:

- complex inspection of the power units;

- modernization of the power units in order to increase their safety;

- justification of the residual life of the irreplaceable equipment, replacement of the equipment that has expired its life; and

- preparation of reports on the in-depth safety assessment of Units 3 and 4 after their life is extended.

The life of the entire NPP power unit was determined by the life of the reactor vessel as the largest "irreplaceable" component (NP-096-15 2015). The vessel life was determined by the strength of Weld 4 (Fig. 1). The specificity of Weld 4 (W 4) of the VVER-440 reactor plants is primarily determined by its location on the vessel in the zone of maximum fluence and the features of welding works performed in the 60-70s. Radiation embrittlement of the weld material is significantly higher than that of the base metal (Gurovich et al. 1997). This is due to a higher content of impurities in the weld material compared with the base metal and relatively lower radiation resistance of the weld material of welds due to the characteristics of their microstructure (grain structure, non-metallic inclusions, etc.) (Gurovich et al. 1997, Alekseenko et al. 1981, Amaev et al. 1997).

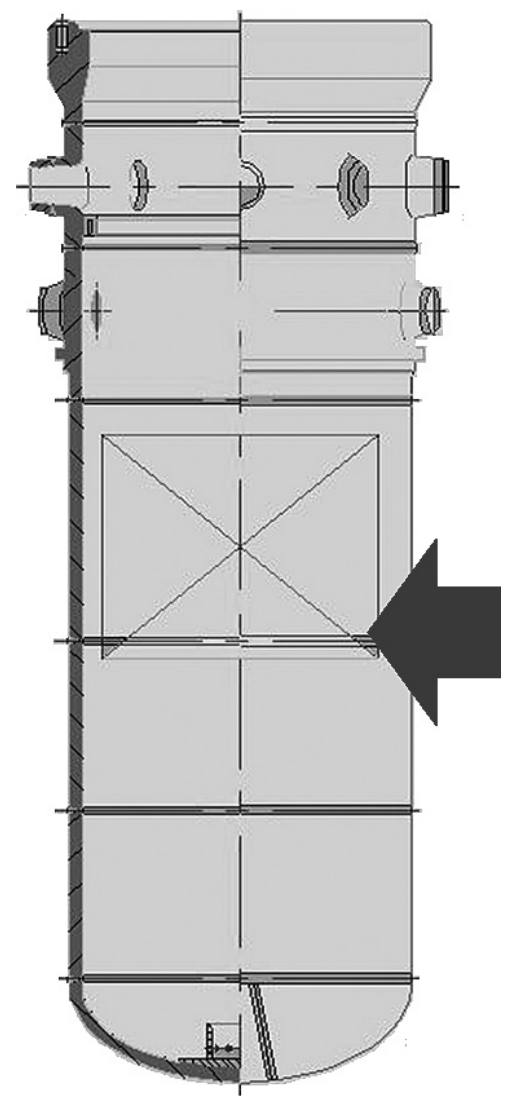

Figure 1. Weld 4 location on the VVER-440 vessel.
A detailed analysis of the accumulated factual material (templates) conducted by qualified material specialists and performance calculations showed that the reactor vessels of Novovoronezh-3 and -4 meet the brittle strength criteria in normal operation and emergency modes for an additional 15-year period (Shtrombakh et al. 2006, Yerak 2013). Table 1 summarizes all the data on measures to ensure the brittle strength of the considered reactor vessels.

In order to extend the service life of Units 3 and 4 up to 45 years, the following measures were developed to improve their safety:

- independent safety system (SS) channels were created;

- the equivalent break section for the maximum design-basis primary-leak accident was increased from $\mathrm{DN}=32 \mathrm{~mm}$ to $\mathrm{DN}=100 \mathrm{~mm}$;

- the leak-before-break concept was introduced for the primary pipelines $(\mathrm{DN}=500 \mathrm{~mm}$ and $\mathrm{DN}=200$ $\mathrm{mm})$; and

- the total probability of severe accidents was reduced to the value of $1 \cdot 10^{-5}$, recommended by Basic Safety Guidelines OPB-88/97.

The following results were achieved:

- the deviations of Categories 3 and 4 (according to the IAEA classification) from the regulatory requirements were eliminated;

- according to the results of the first level PSA, the core damage frequency decreased to $3.44 \cdot 10^{-5}$ reactor-years $^{-1}$ at Unit 3 and to $5.12 \cdot 10^{-5}$ reactor-years $^{-1}$ at Unit 4; and

- the safety assessment of Units 3 and 4 showed the possibility of their further safe operation for 15 years.

Table 1. Works performed on Novovoronezh-3 and -4 in order to extend the lives of their vessels.

\begin{tabular}{lcc}
\hline \multicolumn{1}{c}{ Unit 3 } & Year & Unit 4 \\
\hline Reactor vessel annealing. & 1987 & \\
$\begin{array}{l}\text { Mode: } T=430{ }^{\circ} \mathrm{C}, t=150 \mathrm{~h} \\
\text { Selecting templates from }\end{array}$ & 1991 & $\begin{array}{l}\text { Selecting templates from } \\
\text { Weld } 4 \text { and base metal of }\end{array}$ \\
the reactor vessel shell & & Weld 4 and base metal of \\
Reactor vessel annealing. & & the reactor vessel shell \\
Mode: $T=475 \pm 15^{\circ} \mathrm{C}$, & & Reactor vessel annealing. \\
$t=100 \mathrm{~h}$ & Mode: $T=475 \pm 10^{\circ} \mathrm{C}$, \\
& & $t=150 \mathrm{~h}$
\end{tabular}

Selecting templates from Weld 4 and base metal of the reactor vessel shell Selecting templates from Weld 4 and base metal of the reactor vessel shell Selecting templates from Weld 4 and base metal of the reactor vessel shell
Selecting templates from Weld 4 and base metal of the reactor vessel shell

1995 Selecting templates from Weld 4 and base metal of the reactor vessel shell 


\section{The concept and implemented decisions on re-modernization of NVNPP Unit 4 to extend their service life up to 60 years}

The results of the first service life extension (SLE) of Novovoronezh-3 and - 4 clearly showed that it would be technically possible to further extend their service lives. At the same time, the condition of the components of Unit 3 (upper unit, reactor vessel, steam generators, etc.) required significantly more work during the SLE as compared to those of Unit 4 (Asmolov et al. 2014).

The Scientific and Technical Council of OJSC Concern Rosenergoatom, by its decision of 06.29.2012, recommended that Unit 3 be shut down at the end of its 45 -year service life and a set of documents be developed to justify the expediency of extending the service life of Unit 4 over 45 years, taking into account (NP-096-15 2015, NP-017-18 2018):

- the systems and equipment of Unit 3 used to enhance the safety of Unit 4 (including combined sealed compartments, jet-vortex condenser of Unit 3 , active and supporting safety systems of Unit 3 connected to Unit 4, and other technical solutions);

- the upgraded safety systems of the power unit and a set of measures taken to eliminate the consequences of beyond-design-basis accidents at the unit, minimize the impact on the population and the environment, and define technologies and tools for implementing these measures, taking into account the events that occurred at the Fukushima NPP;

- the possible life re-extension of the irreplaceable reactor equipment, including the reactor vessel, support structures and annular tank; and

- the SLE cost efficiency.

The main problem was the ECCS composition that did not meet the requirements of the current regulatory documents in the field of atomic energy use, in particular, when the full range of loss of coolant accidents (up to LOCA - DN 500) is considered. Therefore, one of the main goals in the concept of improving the level of safety during Unit 4 service life extension up to 60 years was to expand the range of design-basis accidents up to the MCP (DN 500) rupture. For this end, the following technical solutions were proposed:

- to upgrade the ECCS to provide the reactor core cooling during the primary pipeline $(\mathrm{DN}=500 \mathrm{~mm})$ break (MDBA in the event of a LOCA);

- to introduce a passive core cooling system (ECCS accumulator tanks);

- to introduce a low pressure emergency core cooling system (emergency feed pumps for the low-pressure primary circuit); and

- to upgrade the reactor containment so that it remains intact during the above MDBA and the established criteria for radiological consequences are not violated.

In general, according to the project of extending the life of Novovoronezh- 4 over 45 years, more than 40 measures have been implemented.

\section{The structure of the high pressure emergency core cooling system}

The concept of re-extending the service life of Unit 4 provided for a safety level increase by expanding the spectrum of design-basis accidents up to the MCP $(\mathrm{DN}=500 \mathrm{~mm})$ rupture. This goal was achieved by creating four channels of the high pressure emergency core cooling system. Two channels are formed by 4EFP-1, -2 and 4EFP-5, -6 pumps and two additional channels are formed by 3 EFP-1, -2 and 3EFP-5, -6 pumps (Fig. 2).

The existing 3EFP-3,4 have been transferred to the controls of beyond-design-basis accidents (BDBA). These pumping units are supposed to be used to perform safety functions (core cooling) in the event of extreme

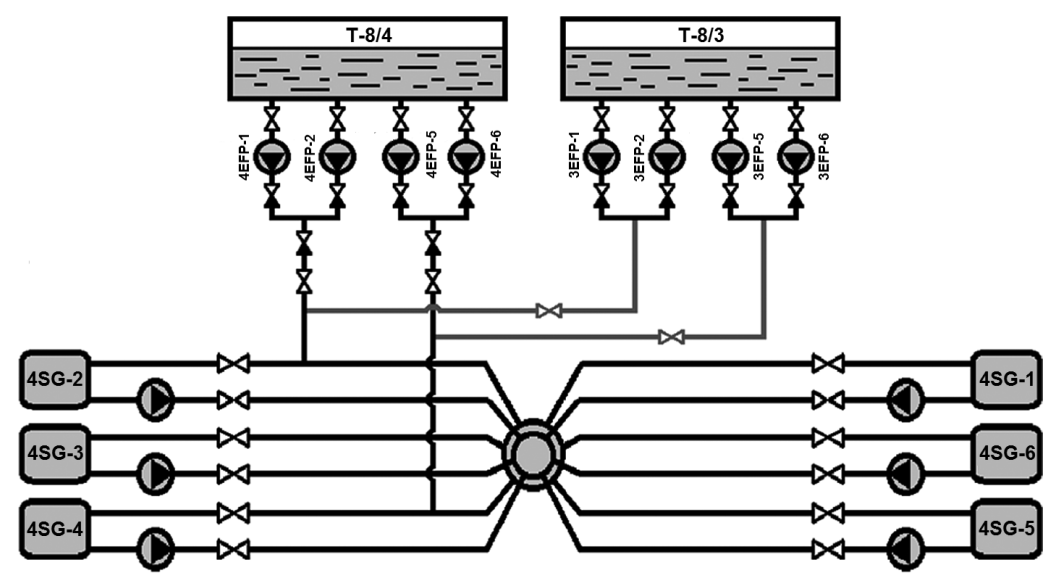

Figure 2. High pressure emergency core cooling system (HP ECCS) as part of pumps 4EFP 1,2,5,6 and additional pumps 3EFP-1,2,5,6. 
external influences causing the failure of existing design tools (as redundant 3,4APN-1, -2, -5, -6).

The estimates made by OKB Gidropress for an accident with the "MCP $(\mathrm{DN}=500 \mathrm{~mm})$ break" initiating event indicate that the temperature of the fuel elements does not exceed $800{ }^{\circ} \mathrm{C}$, i.e., depressurization of initially hermetic fuel elements in this accident is not predicted.

\section{The low pressure emergency core cooling system}

The system is designed as an emergency one to have no single point of failure and ensure the supply of boric acid solution from T-8/3,4 tanks in all design-basis accident modes associated with the primary leak. The emergency core cooling system (passive ECCS) comprises four hydro-accumulators (two channels of two ECCS accumulator tanks), while the low pressure emergency core cooling system (LP ECCS) uses newly mounted low pressure safety injection pumps EFP-1, -2, -3 (three channels with one pump in each) (Fig. 3).

\section{The spray system and combined sealed compartments}

After the service life of Unit 4 was extended to 45 years, as a result of modernization, the containment was equipped with a jet-vortex condenser (4JVC), which made it possible to increase the range of design-basis accidents before the event associated with the pipeline $(\mathrm{DN}=100 \mathrm{~mm}$ ) rupture. However, the expert assessment showed that the occurrence of an accident associated with a double-ended guillotine $\mathrm{MCP}(\mathrm{DN}=500 \mathrm{~mm})$ break will lead to an excess of the maximum design pressure in the containment. In order to reduce the pressure during a hypothetical accident, the sealed compartments of the two units were combined by a jumper in the form of three steel communication pipelines (DN $=1620 \mathrm{~mm}$ ) with a total area of $S=6,18 \mathrm{M}^{2}$ for the gas flow to pass. In doing so, all the requirements of modern regulatory documentation were taken into account, and the complete gas medium flow through the steel communication pipelines during a design-basis accident was ensured, including compliance with seismic resistance standards (Fig. 4). In addition, the simultaneous operation of two

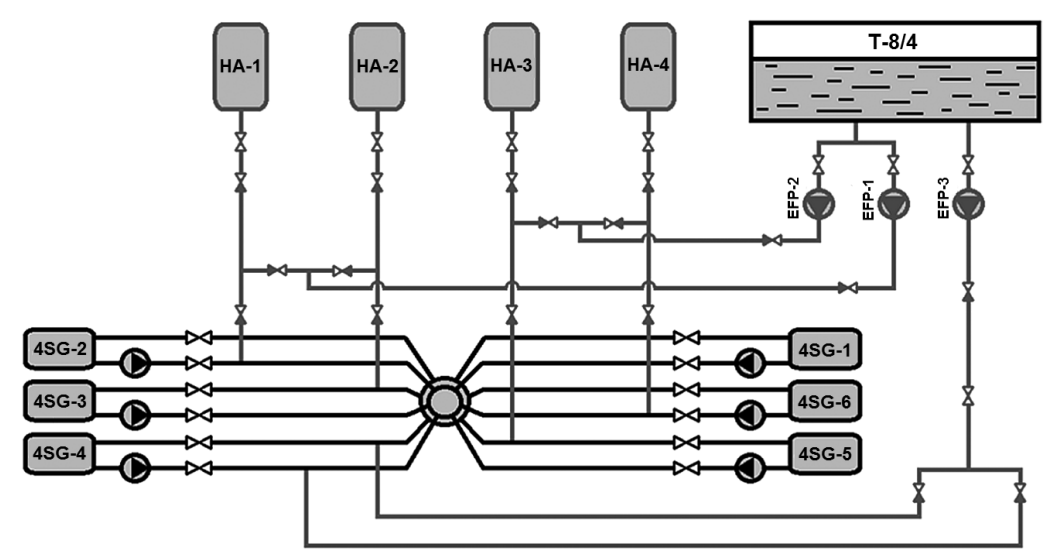

Figure 3. Passive emergency core cooling system (ECCS accumulator tanks) and low pressure safety injection system as part of pumps EFP-1,-2,-3 (LP ECCS).

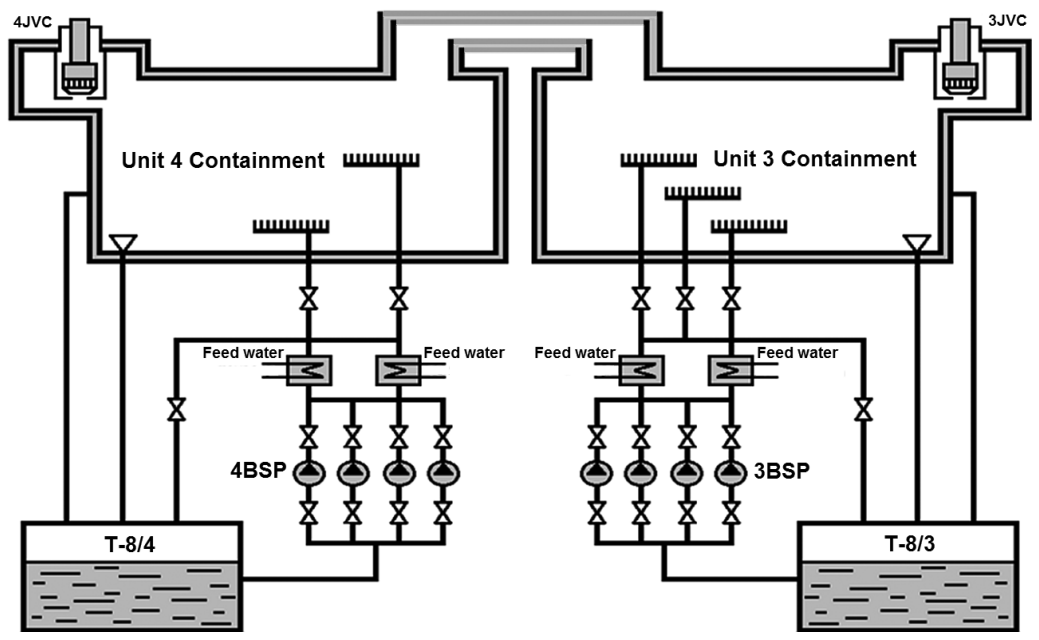

Figure 4. Combined sealed compartments of Units 3 and 4. Containment spray system of Units 4 and 3 with boric spray pumps 4BSP-1,-2,-3,-4 and 3BSP-1,-2,-3,-4. 
JVC (3JVC and 4JVC) and the spray system of the combined containments of Units 3 and 4 in an accident also increase the safety level of Unit 4, due to the non-exceedance of the established criteria for radiological consequences, and ensure the reactor containment integrity.

The spray system's function is to maintain the temperature of the boron solution in the tank T-8/3,4 in the range from 55 to $65{ }^{\circ} \mathrm{C}$ in all modes when emergency reactor feeding from the tank T-8/3,4 may be required.

\section{Assessment of the main irreplaceable equipment life extension capability}

Reactor vessel. To make a decision on Unit 4 re-modernization, one of the main issues was a correct and complete performance assessment of the reactor vessel exposed to severe radiation during operation.

Assessments of the neutron fluence on the reactor vessel walls made by the OKB Gidropress specialists showed the following:

- for Weld 4 of Unit 4 reactor vessel, after recovery annealing in 1991, the dependence of radiation embrittlement is determined to the neutron fluence $\Phi=1.6 \cdot 10^{20}$ neutron $/ \mathrm{cm}^{2}$ (from the time of annealing), which is achieved in 55 years of reactor operation, i.e., in 2027;

- for the reactor vessel base metal, the dependence of radiation embrittlement is determined to the neutron fluence $\Phi=3 \cdot 10^{20}$ neutron $/ \mathrm{cm}^{2}$ (the fluence value up to which $15 \mathrm{H} 2 \mathrm{MFA}$ steel is certified), which is achieved after 50 years of reactor operation, i.e., in 2022.

The main factor in determining the the reactor vessel life is its justification for brittle fracture resistance (BFR) (Yerak 2013, PNAE G-7-002-86 1989). In support of this, the following activities were previously carried out:

- at the periphery of the core, cassettes with "low" neutron leakage were installed to reduce the neutron fluence on the base metal and Weld 4 metal;

- the reactor "freezing" protection interlocks were introduced for accidents with the secondary steam line break; and

- Weld 4 metal was annealed during the PPM-91.

To extend the service life of the reactor vessel of Novovoronezh- 4 over 45 years, a second recovery annealing was carried out at a temperature of $\pm 15^{\circ} \mathrm{C}$ for 150 hours. The justification for extending the service life of the reactor vessel of Unit 4 over 45 years took into account the recovery of metal properties in the areas of guaranteed annealing (at a temperature of $475 \pm 15^{\circ} \mathrm{C}$ ) and temperature gradient $\left(420-460{ }^{\circ} \mathrm{C}\right)$. The novelty and distinctive feature of the second reactor vessel annealing of Unit 4 from the beginning of its operation is that, in addition to Weld 4 , the core shell was subjected to annealing with a total annealing zone of $2340 \mathrm{~mm}$ (from $282 \mathrm{~mm}$ below the weld axis to $2058 \mathrm{~mm}$ above Weld 4 axis). The decision to expand the annealing zone was made due to the fact that the fluence that can be accumulated during operation up to 60 years on the core shell will exceed $3.0 \cdot 10^{24} \mathrm{M}^{-2}(E>0.5 \mathrm{MeV})$, to which the workability of steel $15 \mathrm{H} 2 \mathrm{MFA}$ is substantiated. After the reactor vessel was re-annealed, positive results were obtained in extending the reactor vessel life up to 60 years and guaranteed values of the strength properties and critical brittleness temperature were determined for the reactor vessel metal, primarily for Weld 4 as the most critical reactor component with respect to brittle fracture (PNAE G-7-002-86 1989, RD EO 0421-02 2012).

The greatest danger for the reactor vessel brittle fracture resistance is represented by emergency ECCS actuation conditions - they are decisive in terms of the reactor vessel integrity and service life. Welds 4 and 5 as well as the upper shell are the most dangerous (decisive) components of the reactor vessel irradiated part in terms of its brittle fracture resistance. The nozzle zone is the decisive component of the reactor vessel non-irradiated in terms of its brittle fracture resistance. Therefore, in the course of modernization, water heating was implemented in the ECCS accumulator tanks. Maintaining the water temperature in the ECCS at or above $55^{\circ} \mathrm{C}$ will reduce the thermal effects on the cylindrical part of the reactor vessel when the system is actuated in emergency situations.

The calculation results documented in 179-R-260 "Analysis of the NvNPP Unit 4 reactor vessel radiation durability" clearly indicate that the reactor vessel radiation durability is ensured until the end of the design life (MT 1.1.4.02.1204-2017 2017).

The analysis of the experience in operating the parts of the main joint seal assembly and other internals showed a high level of reliability. There were no failures that would lead to the reactor shutdown during operation. The service life of the reactor vessel and internals is longer than the design period due to the implemented measures to ensure the reactor vessel radiation durability beyond the design life, including annealing of Weld 4 metal and the base metal of the upper and middle shells during PPM-2018.

The steam generators of NvNPP Unit 4 have been in operation since 1972. An analysis of their operating experience has shown that the steam generators are highly reliable: no systematic failures have been identified, which would indicate a low quality of manufacture or installation of the equipment, its significant wear or problems with maintenance and personnel actions during operation.

The condition of the heat exchange tubes ensures that the SGs are operational for the planned period of 60 years subject to compliance with the requirements for operating SGs and, in particular, for maintaining the secondary circuit water chemistry (Margulova and Martynova 1987).

In justification of the strength of the SG components, calculations were made for an extended list of modes, including both modes with normal operating conditions (NOC), anticipated operational occurrences (AOO) and 
emergency situations (ES) as well as a new list of modes for the new configuration of the power unit. The calculations confirmed that the geometrical dimensions of the main SG components do not exceed those adopted in the design, and the stresses from the internal pressure and other loads in the calculated components do not exceed the admissible ones (Karzov et al. 1993, Kutepov 1986).

The calculated SG component static and cyclic strengths showed that all the components satisfy the requirements (MT 1.1.4.02.1205-2017 2017) in the whole range of safe operation modes for 60 years.

The general technical condition of Unit 4 steam generators, the base metal and the metal of the heat exchange tubes as well as the number of plugged tubes in each steam generator (see Table 2) allow further operation and service life until December 29, 2032.

The number of plugged tubes in the steam generators does not exceed $5 \%$ of the total number of SG heat exchange tubes.

Conditions of fuel rods and the core during a maximum design-basis accident. The results of the thermal-hydraulic analysis of the "MCP (DN $=500 \mathrm{~mm})$ break" accident initiating event for Unit 4 show that the temperature of the fuel element claddings does not exceed $800{ }^{\circ} \mathrm{C}$. The changes in the reactor coolant parameters and the operating conditions of the fuel rods during the accident in question can be considered qualitatively coinciding with the propagation of a similar accident in the VVER-440/ 213 reactor, which also confirms the absence of plastic deformations of the fuel claddings.

Thus, it is shown that the modern configuration of security systems allows for core cooling in the considered initiating event. In order to expand the range of design-basis accidents up to the MCP $(\mathrm{DN}=500 \mathrm{~mm})$ break, in addition to upgrading the safety injection system described above, it is necessary to ensure the integrity of the existing fourth physical barrier, i.e. reactor containment and heat removal to the final absorber. This goal is achieved by combining the sealed compartments of Units 3 and 4 . At the same time, the pressure in the reactor containment at the initial stage of the MCP break is limited not only by the increased containment volume but also by the operation of two JVCs. At subsequent stages, steam condensation in the sealed compartments and heat removal occurs while the spray systems of Units 3 and 4 are working.

Justification of seismic resistance of the reactor equipment and pipelines During the initial reactor life extension for Units 3 and 4 no calculations were made to verify the seismic resistance of the equipment and pipelines, since the intensity of the maximum design earthquake for the NvNPP site was estimated at that time to be 4.5 on the MSK-64 scale. For this level of seismic impacts, resistance testing is allowed to be carried out not in strict compliance with the standards for strength calculation of power unit equipment and pipelines (PNAE G-7-002-86 1989).

The experience of extending the reactor life of Unit 5 showed that, at the present stage, Rostekhnadzor requires
Table 2. Condition of Unit 4 Steam Generators.

\begin{tabular}{lllllll}
\hline \multicolumn{1}{c}{ Parameter } & \multicolumn{5}{c}{ Steam generator } \\
\cline { 2 - 7 } & SG-1 & SG-2 & SG-3 & SG-4 & SG-5 & SG-6 \\
\hline Plugged tubes, pes & 117 & 111 & 61 & 128 & 169 & 205 \\
Plugged tubes, \% & 2.11 & 2.00 & 1.10 & 2.31 & 3.05 & 3.70 \\
\hline
\end{tabular}

the seismic resistance to be justified regardless of the site location. Since the NvNPP location is not seismically active, the quality of the monitoring network can be assessed by its ability to record local industrial explosions and earthquakes from remote seismic zones.

The calculated effects for the verification estimates of the seismic stability of Unit 4 facilities (intensity 6 on the MSK-64 scale, acceleration $0.036 \mathrm{~g}$ and corresponding reaction spectra and accelerograms) are determined by the deterministic (scenario) method and conservatively attributed to the effects of the MDE level (maximum design earthquake).

Similarly, since it is impossible to perform a comprehensive probabilistic seismic hazard analysis for the NvNPP site, seismic effects of the DE level are proposed in the following terms: 1 point lower for intensity (i.e. 4 on the MSK-64 scale) and two times lower for acceleration (i.e. $0.018 \mathrm{~g}$ ).

\section{Conclusion}

The analysis of design-basis accidents shows that, when any initial events of design-basis accidents occur at Unit 4, the acceptance criteria and, accordingly, the design limits adopted for design-basis accidents are not violated. In accordance with the main provisions of the "Concept of re-extending the life of Unit 4 at the Novovoronezh NPP KHC-265K (04-08) 2012, Rosenergoatom JSC, 2012", the following goals were achieved:

- to increase the safety level by expanding the range of design basis accidents up to the MCP (DN $=500$ $\mathrm{mm}$ ) break;

- to increase the resistance of the power units to extreme external natural and man-made impacts;

- to justify the possibility of re-extending the life of the irreplaceable reactor equipment, including the reactor vessel; and

- to ensure the SLE cost efficiency.

As a result of the comprehensive modernization, the safety level of Unit 4 was increased due to the expansion of the range of design-basis accidents up to the MCP (DN $=500 \mathrm{~mm}$ ) break. To achieve this goal, more than 40 measures have been implemented (for example, a backup control panel was installed, the safety control systems were replaced with modern ones, etc.).

After the modernization, the active systems comply with the requirements of the single-failure and independence principles according to (NP-001-15 2016), and the 
protection against system common cause failures has been enhanced. Thus, the requirements of paragraphs 3.4.2.1, 3.4.2.7 (NP-001-15 2016), and paragraph 38 (NP-026-16 2016) are satisfied.

According to the results of the probabilistic safety analysis (PSA), it can be concluded that the frequency of the limiting accidental release does not exceed $4,0 \cdot 10^{-7} 1 /$ year. In accordance with (NP-001-15 2016), the cumulative probability of a large accidental release for a single
NPP unit equal to $1.0 \cdot 10^{-7}$ over a one-year interval is considered as a target for a probabilistic safety indicator.

The estimates obtained are close to the target and indicate that the design of Novovoronezh-4, taking into account the modernization measures, meets the most advanced requirements for ensuring public safety, while expanding the spectrum of design-basis accidents, increases its resistance to any external natural and man-made impacts declared in the Concept of re-extending the life of Unit 4.

\section{References}

- Alekseenko NN, Amaev AD, Gorynin IV, Nikolaev VA (1981) Radiation embrittlement of steel bodies of water-water reactors. Moscow. Energoizdat Publ., 191 pp. [in Russian]

- Amaev AD, Kryukov AM, Neklyudov IM, Parshin AM, Platonov PA, Tikhonov AN, Khlopkin NS, Shtrombakh YaI (1997) Radiation damageability and performance of structural materials. St. Petersburg: Politekhnika Publ., 312 pp. [in Russian]

- Asmolov VG, Povarov VP, Vitkovsky SL, Berkovich VYa, Chetverikov AE, Mozul IA, Semchenkov YuM, Suslov AI (2014) The concept of extending the life of power units with a VVER-440 Novovoronezh NPP. Teploenergetika, 2: 16-25. [in Russian]

- Collection of reports (2014) Half a century of ensuring the safety of nuclear power plants with VVER in Russia and abroad. Novovoronezh NPP Publ., 521 pp. [in Russian]

- Gurovich BA, Kuleshov EA, Nikolaev YuA, Shtrombakh YaI (1997) An assessment of the relative contribution of various mechanisms to the radiation embrittlement of reactor vessel materials. Preprint IAE6025/11. Moscow. RNTs KI Publ., 107 pp. [in Russian]

- Karzov GP, Margolin BZ, Shvetsova VA (1993) Physical and mechanical modeling of destruction processes. St. Petersburg: Politekhnika Publ., 391 pp. [in Russian]

- Kutepov AM (1986) Hydrodynamics and heat transfer during vaporization. Moscow. Energoizdat Publ., 448 pp. [in Russian]

- Margulova TKh, Martynova ON (1987) Water regimes of thermal and nuclear power plants. Moscow. Vysshaya Shkola Publ., 318 pp. [in Russian]

- MT 1.1.4.02.1204-2017 (2017) Calculation of the resistance to brittle fracture of the WWER-440 (V-179, B-230) reactor shells, taking into account their annealing when extending the service life to 60 years. The technique. Moscow. Rosenergoatom JSC Publ., 38 pp. [in Russian]
- MT 1.1.4.02.1205-2017 (2017) Calculation of buildings of steam generators of VVER-440 reactor installations (B-179, B-230, B-213) for resistance to brittle fracture when extending the service life to 60 years. The technique. Moscow. Rosenergoatom JSC Publ., 41 pp. [in Russian] - NP-001-15 (2016) General provisions for the safety of nuclear power plants. Moscow. FBU “NTTs YaRB” Publ., 57 pp. [in Russian]

- NP-017-18 (2018) Basic requirements for extending the life of a nuclear power unit. Moscow. FBU “NTTs YaRB” Publ., 21 pp. [in Russian]

- NP-026-16 (2016) Requirements for control systems important for the safety of nuclear power plants. Moscow. FBU "NTTs YaRB" Publ., 30 pp. [in Russian]

- NP-096-15 (2015) Requirements for managing the life of equipment and pipelines of nuclear power plants. The main provisions. Moscow. FBU «NTTs YaRB» Publ., 19 pp. [in Russian]

- Ovchinnikov FYa, Semenov VV (1988) Operational regimes of water-water energy reactors. Moscow. Energoatomizdat Publ., 359 pp. [in Russian]

- PNAE G-7-002-86 (1989) Standards for calculating the strength of equipment and pipelines of nuclear power plants. Moscow. Energoatomizdat Publ., 525 pp. [in Russian]

- RD EO 0421-02 (2012) Methods for predicting the strength characteristics of the material of the reactor vessel during irradiation. Moscow. Rosenergoatom Publ., 7 pp. [in Russian]

- Shtrombakh YaI, Platonov PA, Brak DYu, Nikolaev YuA (2006) Justification of the strength and service life of reactor vessels. Rosenergoatom (the monthly magazine for atomic energy of Russia), 7: 58-59. [in Russian]

- Yerak DYu (2013) Material substantiation of the operation of VVER reactors outside the design service life. Diss. Dr. techn. Sci. Moscow, 229 pp. [in Russian] 